\title{
Contribution of the GP Zones to the Hardening and to the Electrical Resistivity in Al10at.\%Ag Alloy
}

\author{
Faiza Lourdjane*, Azzeddine Abderrahmane Raho* \\ Solids solutions laboratory, physics faculty USTHB, BP 32, El-Alia, Algiers, Algeria \\ *Corresponding author: lourdjane_faiza@yahoo.fr; raho_azzeddine@yahoo.fr \\ Received March 20, 2015; Revised April 03, 2015; Accepted April 07, 2015
}

\begin{abstract}
Using microhardness and electrical resistivity measurements, the contributions of the matrix and that of the Guinier-Preston zones to the hardening and to the electrical resistivity of the Al10at.\%Ag alloy are determined separately during the Guinier-Preston zones precipitation. A linear correlation between the hardness and the electrical resistivity of the as quenched alloys exists. There is also a linear relationship between the contribution of the matrix to the hardening and that to the electrical resistivity of the isothermal aged alloy. However, no linear relation exists between the hardness and the electrical resistivity of the isothermal aged alloy.
\end{abstract}

Keywords: precipitation, transformed fraction, hardness, electrical resistivity

Cite This Article: Faiza Lourdjane, and Azzeddine Abderrahmane Raho, "Contribution of the GP Zones to the Hardening and to the Electrical Resistivity in Al10at.\%Ag Alloy." American Journal of Materials Science and Engineering, vol. 3, no. 1 (2015): 7-10. doi: 10.12691/ajmse-3-1-2.

\section{Introduction}

An Al-Ag supersaturated solid solution evolves towards the equilibrium state following the sequence [1,2,3,4]:

Supersaturated solid solution $\rightarrow$ Guinier-Preston (GP) zones $\rightarrow$ metastable $\gamma^{\text {c}}$-phase $\rightarrow$ equilibrium $\gamma$-phase

The precipitate formation, which results from the diffusion of the solute atoms from the matrix to the precipitate particles, is responsible of a variation of the hardening and the electrical resistivity of the alloy [5]. The alloy hardening results from the interaction between the moving dislocations and the lattice defects. The alloy electrical resistivity results from the interaction between the free electrons and the lattice defects in the alloy. In a non deformed supersaturated solid solution, during an isothermal aging treatment, we can assume that the contribution of the dislocations and that of the grain boundaries to the hardening and to the electrical resistivity remain constant. Thus, the hardness and the electrical resistivity variations are essentially attributed to the interactions of the moving dislocations and the free electrons with the solute atoms and the precipitate particles [6,7]. During an isothermal aging treatment, due to the migration of the solute atoms to the precipitate particles, the contributions of the matrix to the hardening and to the electrical resistivity of the solid solution decrease whereas those of the precipitate phase increase. Our purpose is to determine the contributions of the matrix and the GP zones to the hardening and to the electrical resistivity in the Al-10at.\%Ag alloy.

\section{Experimental Methods}

The Al10\%Ag alloy was prepared by melting $99.99 \%$ and $99.99 \%$ pure aluminum and silver respectively, under an argon protection. After an homogenization at $540{ }^{\circ} \mathrm{C}$ and quenching, the alloys are cut into platelets specimen which are mechanically polished, homogenized at $540^{\circ} \mathrm{C}$, quenched in water and treated at $125^{\circ} \mathrm{C}$. A P1710 Phillips $\mathrm{X}$-ray powder diffractometer, utilizing the monochromatic $\mathrm{CuK}_{\alpha 1}$ radiation, is used for the characterization of our alloys. The microhardness measurements were carried out under a load of 100 gr. Electrical resistivity measurements were carried out using the four points method at room temperature.

\section{Results and Discussion}

\subsection{Characterization of the Solid Solution}

Table 1. Integrated intensities ratios

\begin{tabular}{|c|c|c|}
\hline hkl & $\mathrm{Al}\left(\mathrm{I}_{\mathrm{hkl}} / \mathrm{I}_{111}\right)$ & $\operatorname{Al}-\mathrm{Ag}\left(\mathrm{I}_{\mathrm{hkl}} / \mathrm{I}_{111}\right)$ \\
\hline 111 & 100 & 100 \\
\hline 200 & 50 & 51 \\
\hline 220 & 21 & 30 \\
\hline 311 & 20 & 21 \\
\hline 222 & 6 & 6 \\
\hline
\end{tabular}

The as quenched solid solution, Al10at.\%Ag is characterized by X-ray diffraction. It is well known that an as quenched substitutional solid solution is in a disordered state. In the case of aluminum based solid solutions, the $\mathrm{X}$-ray powder diffraction spectra gives peaks diffraction at the analogous positions of those given by the aluminum. The $\mathrm{Al}$ and $\mathrm{Al}-\mathrm{Ag}$ powder diffraction spectra show that the successive peaks are at analogous positions (Figure 1a,b) 
and their integrated intensities vary in the same ratio (Table 1). The lattice parameters of $\mathrm{Al}$ and $\mathrm{Al}-\mathrm{Ag}$,

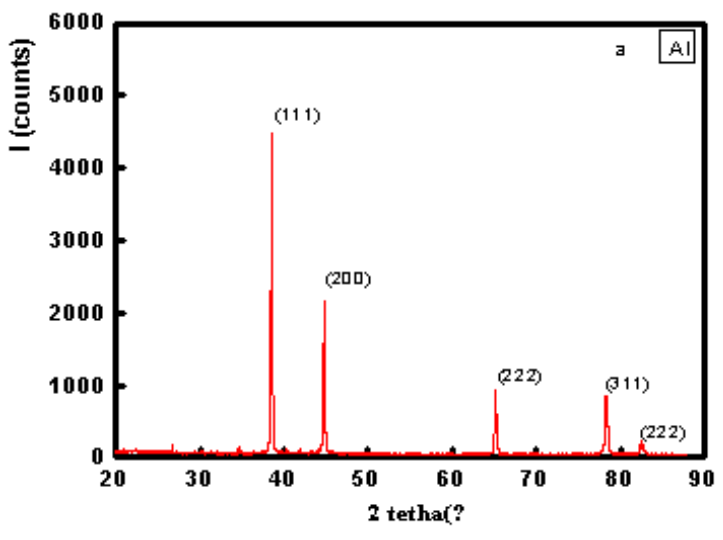

determined using the Nelson-Riley [8] extrapolation function, are respectively 4,0462 $\AA$ and 4,0478 $\AA$.

Figure 1. X-ray powder diffraction spectra of $\mathrm{Al}(\mathrm{a})$ and $\mathrm{Al}-\mathrm{Ag}$ (b) as quenched solid solution

\subsection{Hardening Contributions}

The hardness isotherm curve, established at $125^{\circ} \mathrm{C}$ (Figure 2) shows a first step of hardening due to the GP zones precipitation and a second step due to the precipitation of the metastable $\gamma^{\prime}$ phase. The intermediate bearing corresponds to the metastable equilibrium state of the GP zones precipitation during which their volume fraction is maximum. The softening is due to the coarsening of the particles of the metastable $\gamma$ 'phase and to the precipitation of the particles of the equilibrium $\gamma$ phase.

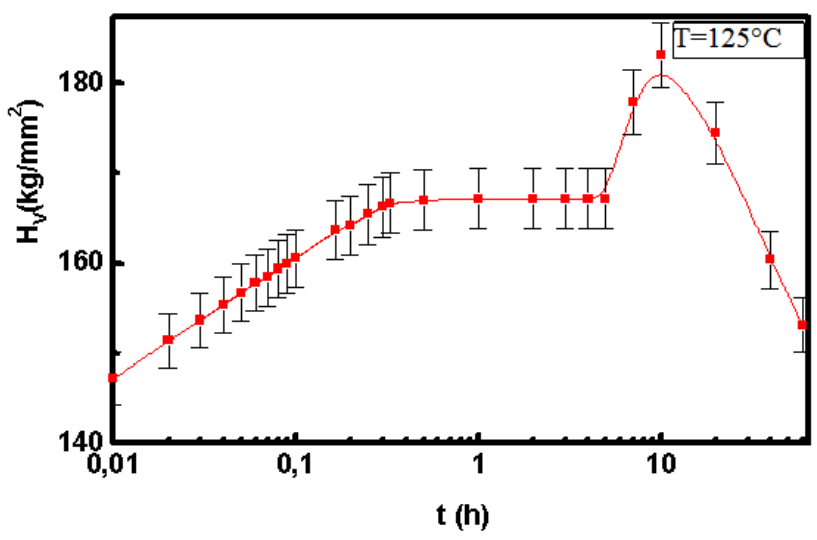

Figure 2. Isotherm hardness curve at $125^{\circ} \mathrm{C}$

During the GP zones formation, the hardness, $H_{v}$, results from the matrix contribution, $H_{v m}$, and the GP zones contribution, $H_{v G P}$ :

$$
H_{v}=H_{v m}+H_{v G P}
$$

The matrix contribution to the hardening, $H_{v m}$, depends on its solute atom concentration, $x_{\mathrm{m}}$. The matrix solute atom concentration during the GP zones formation is determined from the transformed fraction, F. The transformed fraction (Figure 3), is established from the Merle relation [9]:

$$
H_{v}(t)=F \cdot H_{v(\text { metastable equilibrium })}+(1-F) \cdot H_{v}(0)
$$

where $H_{v}(0)$ is the as quenched hardness, $H_{v}(t)$, the hardness of the alloy at the time $t$ during the GP zones

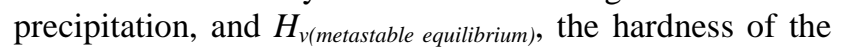
alloy at the metastable equilibrium state of the GP zones

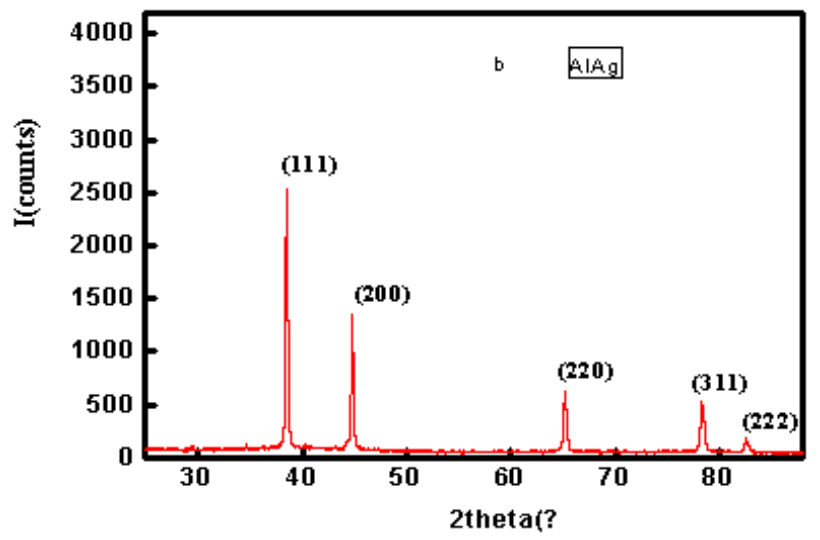

precipitation. The matrix solute atom concentration is obtained using the relation [10]:

$$
F=\left(x_{0}-x_{m}\right) /\left(x_{0}-x_{e}\right)
$$

where $x_{0}$ is the solute atom concentration of the alloy and $x_{e}$, the solute atom concentration of the matrix at the metastable equilibrium state. At $125^{\circ} \mathrm{C}$, the value of $x_{e}$, determined from the metastable equilibrium diagram [11] is 0,53 at. $\%$.

The matrix contribution to the hardening, $H_{v m}$, is deduced from the hardness variation curve of homogenized alloys containing different solute atom concentrations (Figure 4) and the variation curve of the matrix solute atom concentration during the GP zones formation (Figure 5).

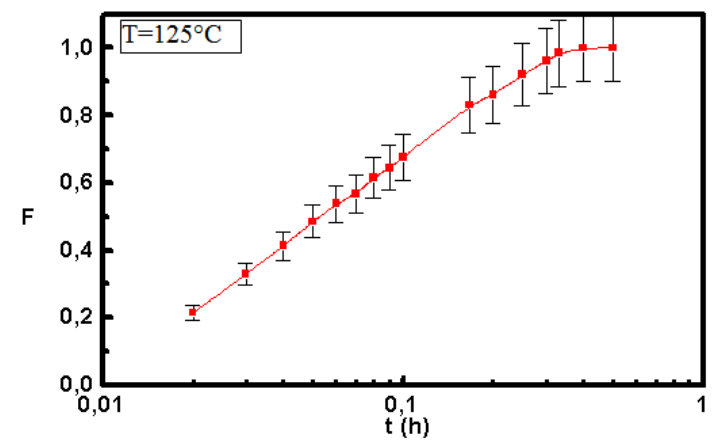

Figure 3. Transformed fraction during the GP zones precipitation at $125^{\circ} \mathrm{C}$

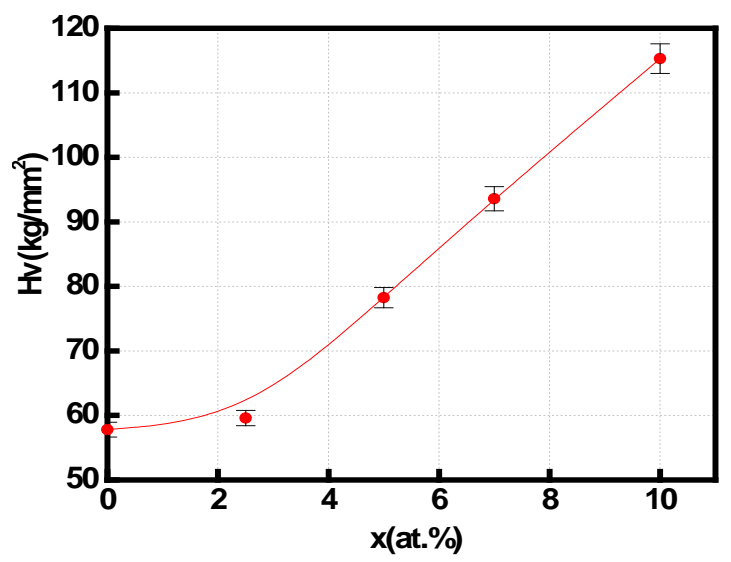

Figure 4. Hardness curve variation of homogenized Alxat.\%Ag alloys 


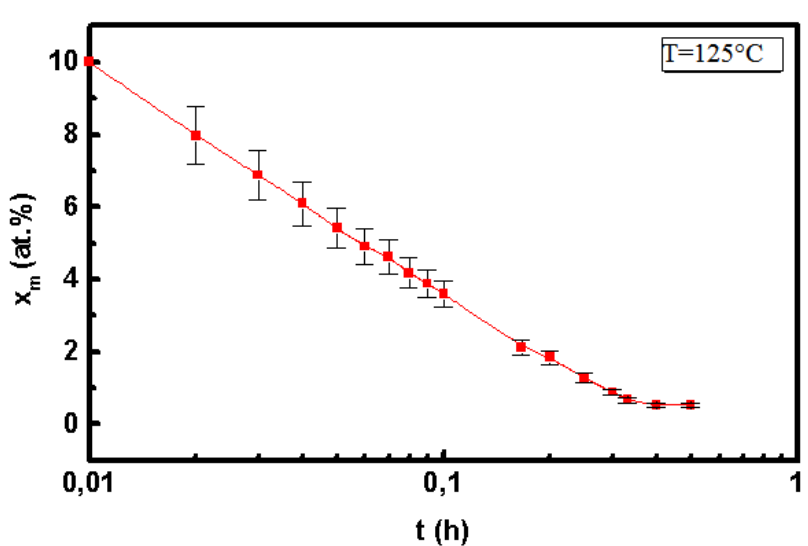

Figure 5. Matrix solute atom concentration during the GP zones precipitation at $125^{\circ} \mathrm{C}$

Thus, the GP zones contribution to the hardness, $H_{v G P}$, is given by the difference $H_{v}-H_{v m}$ (Figure 6).

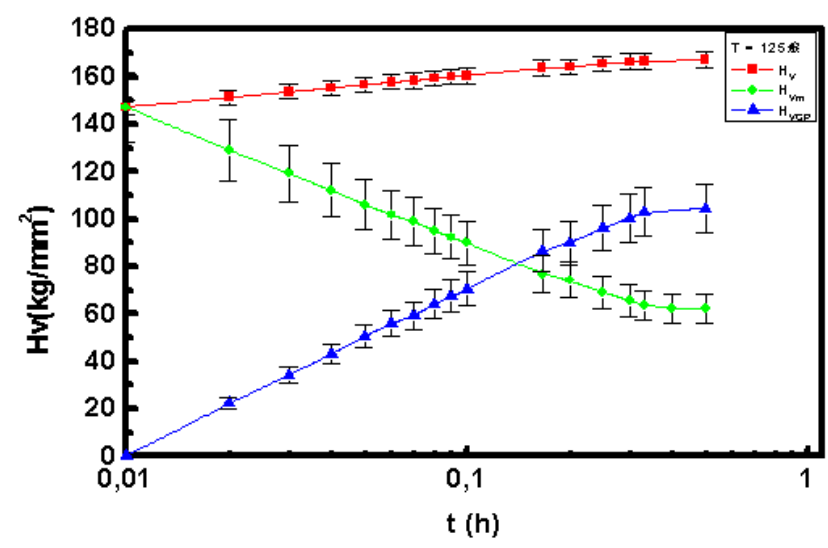

Figure 6. Contribution to the alloy hardening of the matrix, $H_{V m}$, and that of the GP zones, $H_{V G P}$, during the GP zones precipitation at $125^{\circ} \mathrm{C}$.

\subsection{Electrical Resistivity Contributions}

During the GP zones formation, the electrical resistivity of the alloy decreases and reaches a constant value at the metastable equilibrium state (Figure 7) during which the volume fraction of the GP zones is maximum.

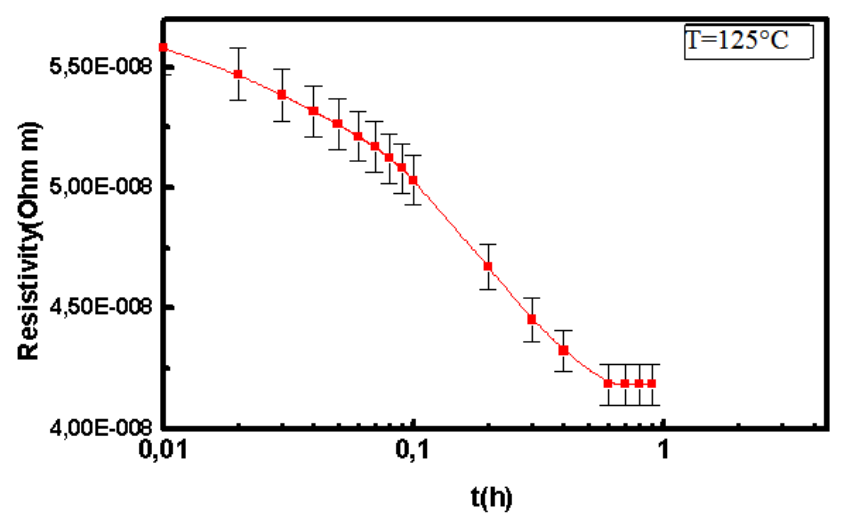

Figure 7. Electrical resistivity variation of the alloy during the GP zones precipitation at $125^{\circ} \mathrm{C}$

According to the Matthiessen rule, the electrical resistivity results from the contribution of the phonons and that of all defects in the alloy such the dislocations, the grain boundaries, the solute atoms and the precipitate particles. During an isothermal aging treatment, the contribution of the phonons remains constant. Also, in a non deformed alloy, during an isothermal aging treatment, the contributions of the defects such the dislocations and the grain boundaries remain constant while those of the solute atoms and the precipitate particles vary.

In an as quenched and non deformed solid solution, during an isothermal aging treatment, the electrical resistivity, $\rho$, results from the contributions of the matrix, $\rho_{m}$, and that of the GP zones, $\rho_{G P}$ :

$$
\rho=\rho_{m}+\rho_{G P}
$$

The electrical resistivity contribution of the matrix is determined from the variation curve of the electrical resistivity of homogenized alloys containing different concentrations of solute atoms (Figure 8) and the variation curve of the matrix solute atom concentration during the GP zones formation (Figure 5). The variation curve of electrical resistivity of homogenized alloys shows an increase of the electrical resistivity with the solute atom concentration [12],

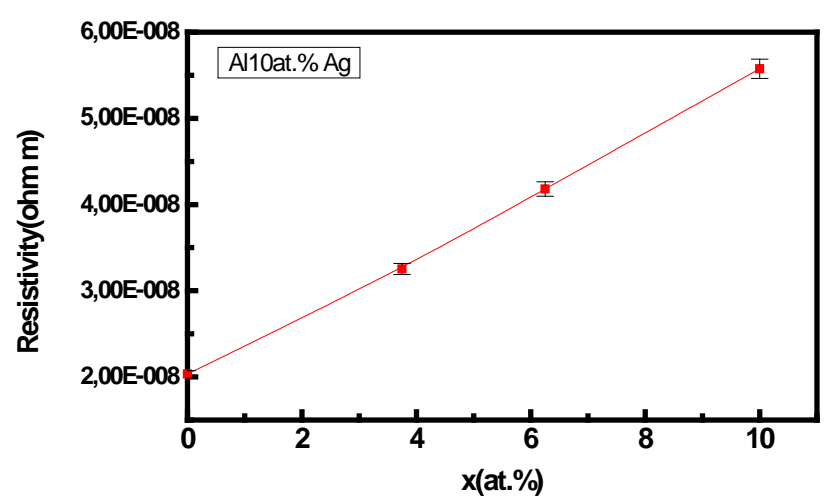

Figure 8. Electrical resistivity of homogenized Alxat.\%Ag alloys.

The GP zones contribution to the electrical resistivity, $\rho_{G P}$, is given by the difference $\rho-\rho_{m}$ (Figure 9).

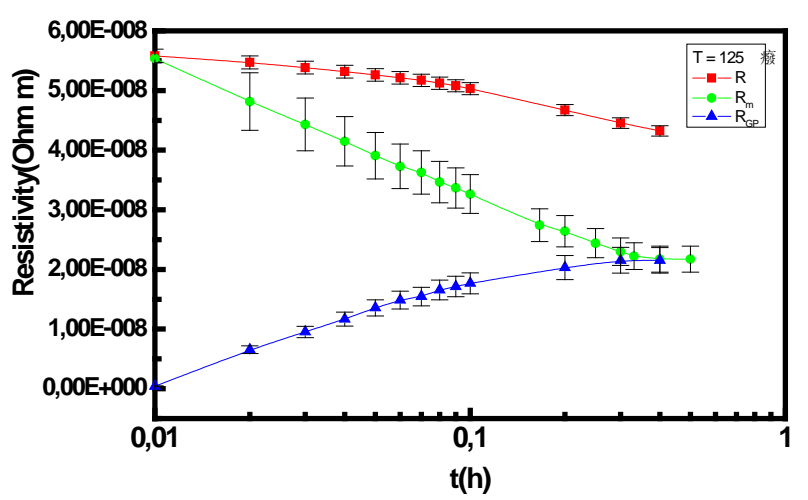

Figure 9. Contributions to the alloy electrical resistivity of the matrix, $\rho_{m}$ and of the GP zones, $\rho_{G P}$, during the GP zones precipitation at $125^{\circ} \mathrm{C}$

\section{Correlation between Hardness and Electrical Resistivity}

A linear relationship is observed between the hardness and the electrical resistivity of the as quenched alloys (Figure 10). In the as quenched alloys, the hardness and the electrical resistivity variations are due only to the presence of the solute atoms. In the isothermal aged alloy, there is, also, a linear relationship between the contributions of the matrix to the hardness and to the 
electrical resistivity of the alloy (Figure 11). However, no linear relation exists between the hardness and the electrical resistivity of the isothermal aged alloy (Figure 12). In the as quenched alloys, the hardness and the electrical resistivity variations are due only to the presence of solute atoms while in the isothermal aged alloy, there are due to the presence of the solute atoms and the GP zones. In such a case, the solute atom concentration of the matrix and the volume fraction of the GP zones vary simultaneously and no linear relation is observed in accordance with the results reported by Koch and Colijn [13].

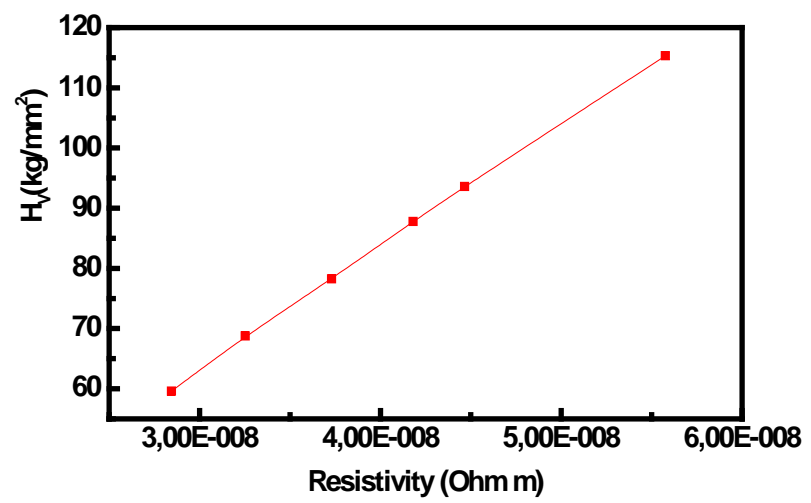

Figure 10. Variation of the hardness versus the electrical resistivity of the as quenched alloys

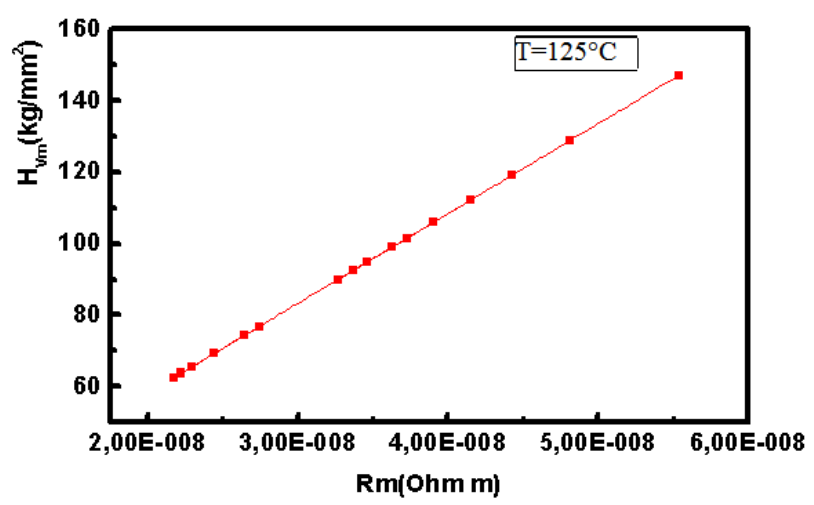

Figure 11. Variation of the hardness contribution versus the electrical resistivity contribution of the matrix during the GP zones precipitation

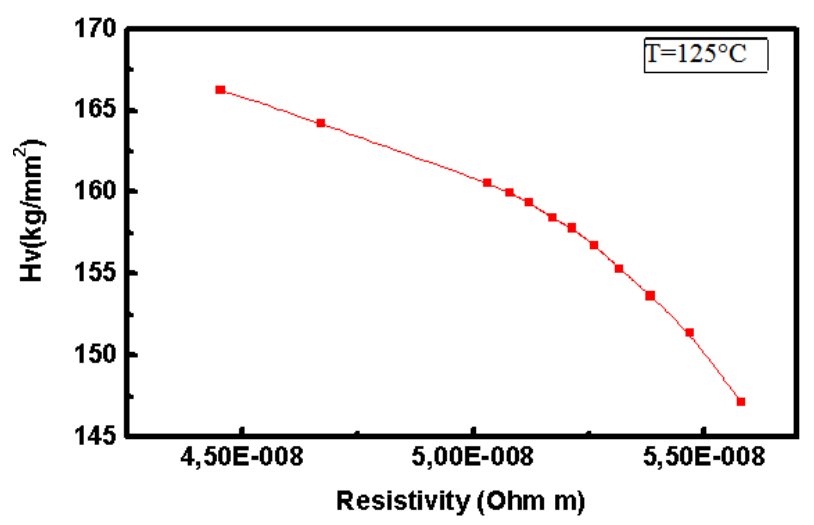

Figure 12. Variation of the hardness versus the electrical resistivity of the isothermal aged alloy

\section{Conclusion}

The contributions of the matrix and those of the GP zones to the hardening and to the electrical resistivity of the Al10at.\%Ag alloy were determined separately. A linear relationship exists between the hardness and the electrical resistivity of the as quenched alloy while no linear relation exists between the hardness and the electrical resistivity of the isothermal aged alloy during the GP zones precipitation.

\section{References}

[1] Koji Inoke, Kenji Kaneko "Severe local strain and the plastic deformation of Guinier-Preston zones in the $\mathrm{Al}-\mathrm{Ag}$ system revealed by three-dimensional electron tomography «Acta Materialia 54 (2006) 2957-2963.

[2] A.M. Abd El-Khalek, «Transformation characteristics of Al-Ag and Al-Ag-Ti alloys » Journal of alloys and compounds 459, (2008) 281-285.

[3] PH, A, Dubey. «Shape and internal structure of Guinier-Preston zones in Al-Ag » Acta metall.mater 39 (1991)1161-1170.

[4] B.Schönfeld, A. Malik, G. Korotz, W.Bürher and J.S.Pedersen «Guinier-Preston zones in $\mathrm{Al}$-rich $\mathrm{Al}-\mathrm{Cu}$ and $\mathrm{Al}$-Ag single crystals».Physica B234-236 (1997) 983-985.

[5] M. Rosen, E. Horowits, L. Swartzendruber, S. Fick and R. Mehrabian: Mater. Sci. and Engineering 53 (1982), p.191.

[6] K.Matsumoto, S.Y. Komatsu, M. Ikeda, B. Verlinden, B. Ratchev, "Quantification of volume fraction of precipitates in an aged Al-1.0 mass\%Mg2Si alloy"MaterialsTransactions, 2000, 41 (10) 1275-1281.

[7] Raeisinia B., Poole W.J., Lloyd D.J., "Examination of precipitation in the aluminum alloy AA6111 using electrical resistivity measurements.” Materials Science and Engineering A, 2006, 420 (1-2), 245-249.

[8] J. B. Nelson, D. B. Riley, “An experimental investigation of extrapolation methods in the derivation of accurate unit-cell dimensions of crystals.”, 3rd Proc. Phys. Soc. London, 57 (1945), p. 160-177.

[9] J, Merlin, P, Merle F.Fouquet, F.Pelletier, “Anelastic phenomena and structural state in aluminium silver alloys." Scripta Metalurgica 12 (3), 227-232, (1978).

[10] J. Røyset and N. Ryum, "Kinetics and mechanisms of precipitation in an Al-0.2 wt.\% Sc alloy." Materials Science and Engineering A 396 (2005), 409-422.

[11] B. Predel and W.Gust. "Diskontinuierliche ausscheidungsreaktionen im system Aluminium-Silber und ihre beeinflussung durch dritte legierungspartner” 10(1), 211-222, (1972).

[12] American Society for Metals. Aluminium: Properties and Physical Metallurgy, 1st ed. (Metals Park, Ohio, 1984:205).

[13] G. H. Koch and D. T. Kolijn: "The heat treatment of the commercial aluminium alloy 7075.” Journal of Heat Treating, Vol.1, No 2 p.3 (1979). 